\title{
pH Effect in Aquatic Fulvic Acid from a Brazilian River
}

\author{
Sérgio da Costa Saab, ${ }^{*}, a$ Eduarda R. Carvalho, ${ }^{b}$ Rubens Bernardes Filho, ${ }^{b}$ \\ Márcia R. de Moura, ${ }^{c}$ Ladislau Martin-Neto ${ }^{b}$ and Luiz Henrique C. Mattoso ${ }^{b}$
}

${ }^{a}$ Departamento de Física, Universidade Estadual de Ponta Grossa, 84030-999 Ponta Grossa-PR, Brazil

${ }^{b}$ Embrapa Instrumentação Agropecuária, 13560-970 São Carlos-SP, Brazil

'Instituto de Física de São Carlos, Universidade de São Paulo, Av. Trabalhador São-carlense, 400, CP 369, 13560-970 São Carlos-SP, Brazil

\begin{abstract}
Estudos do comportamento morfológico dos ácidos fúlvicos foram realizados utilizando a técnica de microscopia de força atômica aliada às técnicas de potencial zeta e espectroscopia de fluorescência. Os resultados mostraram que o ácido fúlvico (AFA) de um rio tropical mudou a sua morfologia quando variado o $\mathrm{pH}$ da solução aquosa dos AFA. Em pH ácido a morfologia é mais granular formando aglomerados de altura entre 10-55 nm. Em pH alcalino os valores foram de 2,5-4,0 nm, sendo que a morfologia em condições alcalinas é aberta formando estruturas não granulares. Estes resultados sugerem que para $\mathrm{pH}$ 3,5 as interações eletrostáticas são fracas e as ligações de hidrogênio são responsáveis pela formação de agregados, enquanto em $\mathrm{pH} 9,0$ as interações eletrostáticas são fortes devido ao aumento da ionização de grupos fenólicos e ocorrem poucas ligações hidrogênio formando estruturas mais abertas. Os resultados de espectroscopia de fluorescência mostraram mudança na estrutura do AFA de rio tropical em $\mathrm{pH}$ alcalino em comparação com a estrutura em pH ácido, corroborando com os resultados obtidos pela AFM.
\end{abstract}

Studies of the morphological behavior of fulvic acids were carried out using the Atomic Force Microscopy technique together with zeta Potential techniques and fluorescence spectroscopy. Results showed that the aquatic fulvic acid (AFA) of a Brazilian River changed its morphology when the AFA aqueous solution had its $\mathrm{pH}$ changed. In acid $\mathrm{pH}$ the morphology is granular forming $10-55 \mathrm{~nm}$ high agglomerates. In alkaline $\mathrm{pH}$ values were $2.5-4.0 \mathrm{~nm}$, and the morphology forms non granular structures. These results suggest that for $\mathrm{pH} 3.0$ electrostatic interactions are weak and hydrogen bonding is responsible for the aggregates formation; while at $\mathrm{pH} 9.0$ electrostatic interactions are strong due to the increase in phenolic groups ionization and low hydrogen interaction forming open structures. Fluorescence spectroscopy results confirmed the AFM, that is, a change in the AFA in tropical river in alkaline $\mathrm{pH}$ compared to the structure in acid $\mathrm{pH}$.

Keywords: humic substances, AFM, fluorescence

\section{Introduction}

Presence of humic substances (HS) in a water supply is undesirable for several reasons, for instance: it produces esthetical problems as color in the water; stabilizes dispersed and colloidal particles during coagulation processes; leads to formation of biodegradable organic compounds during ozonation and thereby enhances regrowth of microorganisms within the water-distribution systems. ${ }^{1}$

Fulvic acids (FA) has been postulated to be one of the most important factors controlling the rates of mineral

\footnotetext{
*e-mail: scsaab@uepg.br
}

dissolution in soils and sediments. ${ }^{2-5}$ Sorbed FA may strongly influence the physical and chemical properties of colloidal particles in natural waters, and as a consequence help to control the transport of organic and inorganic pollutants. In aquatic environments FA is the dominant type of HS. ${ }^{6}$

The study of humic substances structure is carried out through different spectroscopy techniques ${ }^{7-10}$ as well as microscopies. ${ }^{11,12}$ Among these techniques, the fluorescence spectroscopy ${ }^{13,14}$ and the atomic force microscopy $(\mathrm{AFM})^{15-18}$ have been used to characterize and determine the humic substances structure.

Atomic force microscopy (AFM) technique can image surfaces with atomic resolution by scanning a sharp tip 
across the surface at forces smaller than the forces between atoms. ${ }^{15} \mathrm{AFM}$ is a technique which has been employed to study the morphologies of humic and fulvic acid. ${ }^{12,16-18} \mathrm{It}$ is a powerful tool to characterize small colloids, as well as colloid agglomeration, adsorption onto surfaces, or modification in morphologies affected by changes in the physico-chemical properties.

Namjesnik-Dejanovic and Maurice ${ }^{12}$ getting AFM images of FA river reported that four main structures were observed. At low concentrations, sponge-like structures consisting of rings ( $c a .15 \mathrm{~nm}$ in diameter) appeared, along with small spheres (10-50 nm). At higher concentrations, aggregates of spheres formed branches and chain-like assemblies.

Chen and Schnitzer ${ }^{19}$ indicated that at very low $\mathrm{pH}$ humic substances behave like uncharged polymers, whereas at higher $\mathrm{pH}$ they exhibit a polyelectrolytic character.

Fluorescence spectroscopy is a very promising, sensitive and useful technique for the study of environmental samples, like those containing humic substances. The potential utility of this technique for studying the structural and functional chemistry of humic materials is due to the presence of a variety of fluorescent structures present, specially in fulvic acids, which include condensed aromatic moieties bearing various functional groups and unsaturated aliphatic chains.

Carvalho et al., ${ }^{1}$ studying aquatic fulvic acids (AFA) with spectroscopic fluorescence showed that reduction of fluorescence intensity of AFA samples after reaction with chlorine in the region of longer wavelength can be probably associated with selective interaction between aromatic structures of AFA and chlorine. This selective interaction probably contributes for the formation of the intermediates as trihalomethanes.

The objective of this work was to get AFM images of AFA Brazilian river, and used fluorescence spectroscopy and zeta potential with $\mathrm{pH}$ change to verify the structural and morphologic change of the AFA.

\section{Experimental}

\section{Water sample}

The aquatic HS were isolated from a sample collected from a tributary stream of River Itapanhaú within of the State Park called Serra do Mar. This is an environmental protection area located in the seaboard, $7^{\text {th }}$ UGRHI (Unidades de Gerenciamento de Recursos Hídricos) of $11^{\text {th }}$ group of UGRHI from São Paulo State, Brazil

Pereira, a tributary river presents dark water with high content aquatic organic matter, making it easy to obtain and extract material for laboratory reaction with chlorine and chlorine dioxide. This river receives treated sewage from the sewage treatment station (ETE) from the Riviera neighborhood in São Lourenço, about $4.5 \mathrm{~km}$ far from the Serra do Mar in São Paulo State, Brazil.

The geomorphologic situation in the region where João Pereira River is located enabled the development of different formation and vegetable association, mainly those belonging to the restinga (sand coastal plain vegetation) and mangroves, as well as the Atlantic typical rainforest and nearby. The characterization of the region vegetation is the coastal plains, covered by restinga and Atlantic forest, thus developing great variety of subtypes in the same area, due to hydrographic, topographic and microclimate heterogeneity in the region.

\section{Fulvic acids extraction}

All reagents used were high-purity grade, unless otherwise stated. Diluted acid and base solutions necessary for the aquatic HS isolation were prepared by convenient dilution of $30 \%$ (v/v) hydrochloric acid (suprapur, Merck AG) or sodium hydroxide monohydrate (suprapur Merck AG) dissolved in high-purity water (Milli-Q system, Millipore). The XAD 8 resin adsorbent (Serva Feinbiochemica), used for isolation of aquatic HS, was purified before use by successive soaking with $0.5 \mathrm{~mol} \mathrm{~L}^{-1}$ $\mathrm{HCl}, 0.5 \mathrm{~mol} \mathrm{~L}^{-1} \mathrm{NaOH}$ and methanol p.a. (24 h each). For this purpose, $50 \mathrm{~L}$ of surface water were filtered through $0.45 \mu \mathrm{m}$ cellulose-based membranes and acidified with concentrated $\mathrm{HCl}$ solution to $\mathrm{pH}$ 2.0. Afterwards, the aquatic HS from the acidified sample was isolated on the XAD 8 collector following the recommendations of Malcolm. ${ }^{20}$ After elution with $0.1 \mathrm{~mol} \mathrm{~L}^{-1} \mathrm{NaOH}$ solution, the obtained concentrate $\left(4.5 \mathrm{mg} \mathrm{mL}^{-1} \mathrm{DOC}\right.$ equivalent to $9.0 \mathrm{mg} \mathrm{mL}^{-1}$ aquatic $\mathrm{HS}$ ) was acidified to $\mathrm{pH}$ 2.0 with $6.0 \mathrm{~mol} \mathrm{~L}^{-1} \mathrm{HCl}$ solution and the AFA (soluble fraction) were separated of aquatic humic acid (AHA) by centrifugation at $12000 \mathrm{rpm}(40 \mathrm{~min}){ }^{1}$

\section{Elemental analysis}

The elemental composition of the samples in relation to carbon, hydrogen and nitrogen content was determined in an elemental analyzer (EA 1108 from Fisons Instruments). The oxygen level was obtained through difference at $100 \%$, discounting ash levels in the lyophilized samples. In order to determine ash content, $20 \mathrm{mg}$ of each AFA sample was calcined for one hour at $800{ }^{\circ} \mathrm{C}$ in flask. The result was obtained from the arithmetic average of replicated experiments.

The elemental composition percentage values and the AFA ash content are presented in Table 1. 
Table 1. Percentual values of elemental composition and ash content in \%, obtained for the AFA sample

\begin{tabular}{lccccc}
\hline Samples & Ashes / (\%) & N / (\%) & C / (\%) & H / (\%) & $0 /(\%)$ \\
\hline AFA & 10.95 & $1.39 \pm 0.02$ & $47.56 \pm 0.01$ & $4.03 \pm 0.01$ & 46.30 \\
\hline
\end{tabular}

\section{AFM imaging}

The imaging of AFA samples was carried out at two $\mathrm{pH}$ values 3.0 and 9.0. These were used to identify structural changes of FA when the $\mathrm{pH}$ varies. Suspensions of $100 \mathrm{mg} \mathrm{L}^{-1}$ of AFA were prepared by dissolving freeze-dried AFA samples in demineralized water, then shaken for at least three days, while protected from light, before preparation for AFM analysis. Using $\mathrm{HCl}$ the $\mathrm{pH}$ was adjusted to 3.0 and by $\mathrm{NaOH} \mathrm{pH}$ was adjusted to 9.0. Muscovite mica with a surface area about $1 \mathrm{~cm}^{2}$ was cleaved and introduced into a beaker containing $10 \mathrm{~mL}$ of AFA solutions. Suspension of AFA appeared after one day under constant shaking; the mica was allowed to be washed with demineralized water and to air dry in an enclosed Petri dish in a dissecator for at least $12 \mathrm{~h}$ before the AFM images obtaintion.

Images were obtained using the AFM microscope Didimension V, Veeco. Tapping mode was used and Silicon SPM - Sensor with spring constant $42 \mathrm{~N} \mathrm{~m}^{-1}$, resonant frequency $285 \mathrm{kHz}$. Samples were analyzed at $21^{\circ} \mathrm{C}$ and a relative humidity of $35-45 \%$. For each image, the topography, phase and amplitude were recorded. Surface scans of AFM were analyzed using Gwyddion free SPM data analysis software ${ }^{21}$ based on MS-Windows.

\section{Fluorescence spectroscopy}

AFA solutions were prepared in $8 \mathrm{mg} \mathrm{L}^{-1} \mathrm{NaHCO}_{3}$ and $\mathrm{pH}$ values varying from 5 to 11 . Emission spectra were recorded over the range 330-600 nm, with fixed excitation wavelength of $320 \mathrm{~nm}$.

\section{Zeta potential}

For the study of zeta potential in function versus the $\mathrm{pH}, \mathrm{AFA}$ samples in a suspension of $100 \mathrm{mg}$ per $1 \mathrm{~L}$ of distilled water milliQ were used. The suspension was sonicated for $30 \mathrm{~min}$ in a $60 \mathrm{~W}$ bath ultrasound in $20 \mathrm{~mL}$ parts; $\mathrm{pH}$ was adjusted with the addition of $0.1 \mathrm{~mol} \mathrm{~L}^{-1} \mathrm{HCl}$ or $0.1 \mathrm{~mol} \mathrm{~L}^{-1} \mathrm{NaOH}$ at $20^{\circ} \mathrm{C}$ and after $24 \mathrm{~h}$ the $\mathrm{pH}$ was readjusted. The equipment used was Malvern Instruments, Zeta sizer nano ZS model Zen 3600.

\section{Results and Discussion}

Figure 1 shows de AFA AFM images at $\mathrm{pH}$ 3.0. In Figure 1a the image can be seen in $2 \mathrm{D}$, in Figure $1 \mathrm{~b}$, the image in 3D and in Figure 1c the height and diameter of AFA particles on the mica sheet measured from the two straight lines indicated in Figure 1a. Agglomerates in the shape of pyramids, with diameter around 150-300 nm and 10-55 nm high were observed.

Figure 2 shows the AFA AFM images at $\mathrm{pH}$ 9.0. Figure $2 \mathrm{a}$ image indicates a more open distribution of AFA on the mica sheet when compared with Figure 1a image at $\mathrm{pH}$ 3.0. Figure $2 \mathrm{~b}$ shows the image in $3 \mathrm{D}$ confirming

a)
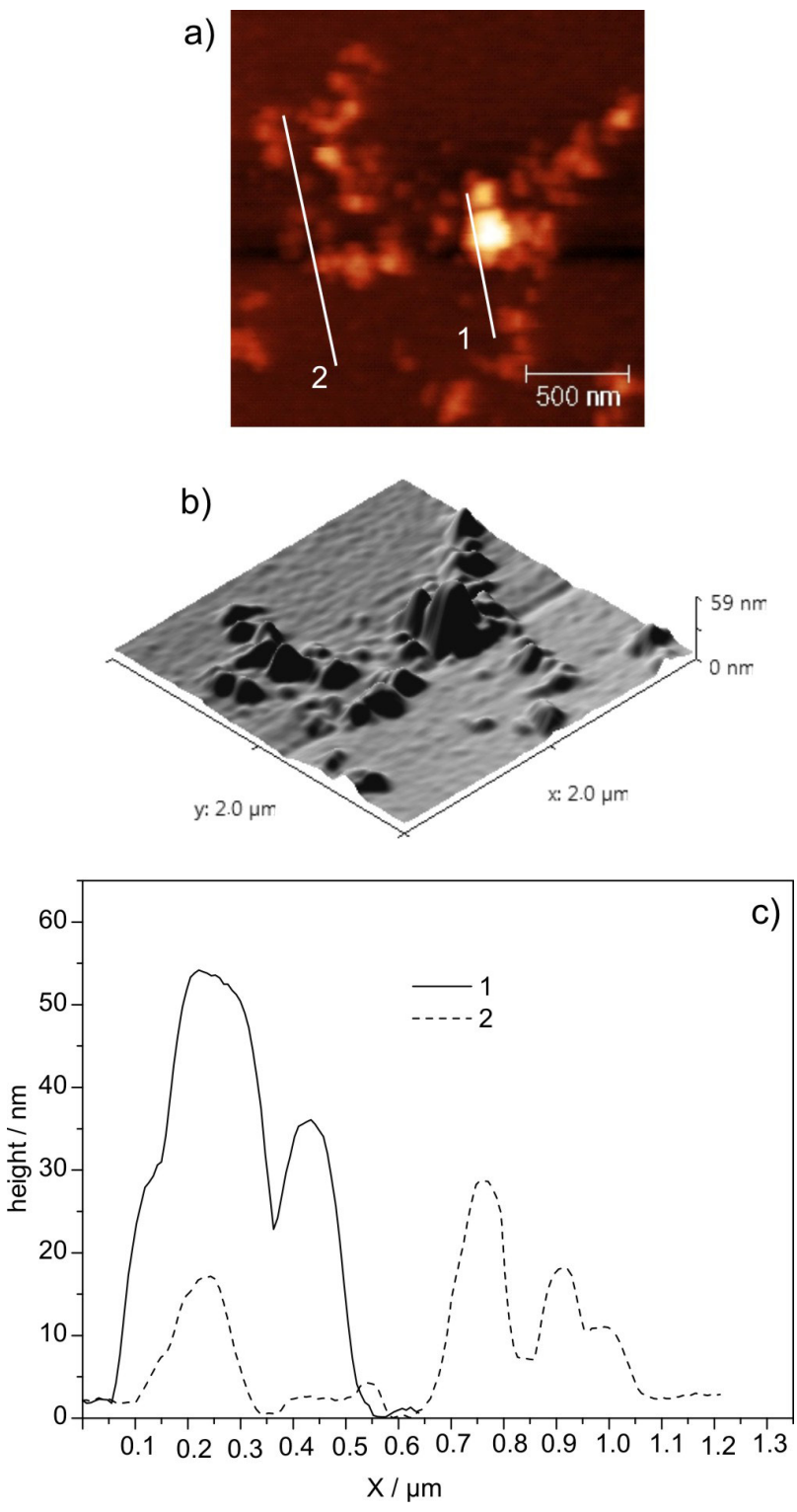

Figure 1. AFA AFM image at pH 3.0 in: a) 2D; b) 3D; c) height in function of images scanning, represented in the segments 1 and 2 from Figure 1a. 
the open image of AFA at pH 9.0. Dimensions can be observed in Figure 2c where the AFA height on the mica at $\mathrm{pH} 9.0$ was between $2.5-4.0 \mathrm{~nm}$ and diameter between $100-300 \mathrm{~nm}$. With $\mathrm{pH}$ increase, AFA particles expand and repel one another electrostratically. Strengths become weaker, due to $\mathrm{H}$ bonding, van der Waals interactions and interactions of $\pi$ electrons from adjacent molecules, with dissociation of carboxylic and phenolic groups, generating negative charges ${ }^{22}$ as shown in Figure 3 (zeta potential).

Figure 3 shows the zeta potential variation with the $\mathrm{pH}$ of the river AFA sample. Zeta potential becomes more negative with the increase of the $\mathrm{pH}$. There is a sharp increase in the negative charge from $\mathrm{pH}$ 7.0. This fact matches with the beginning of phenolic acid groups

a)
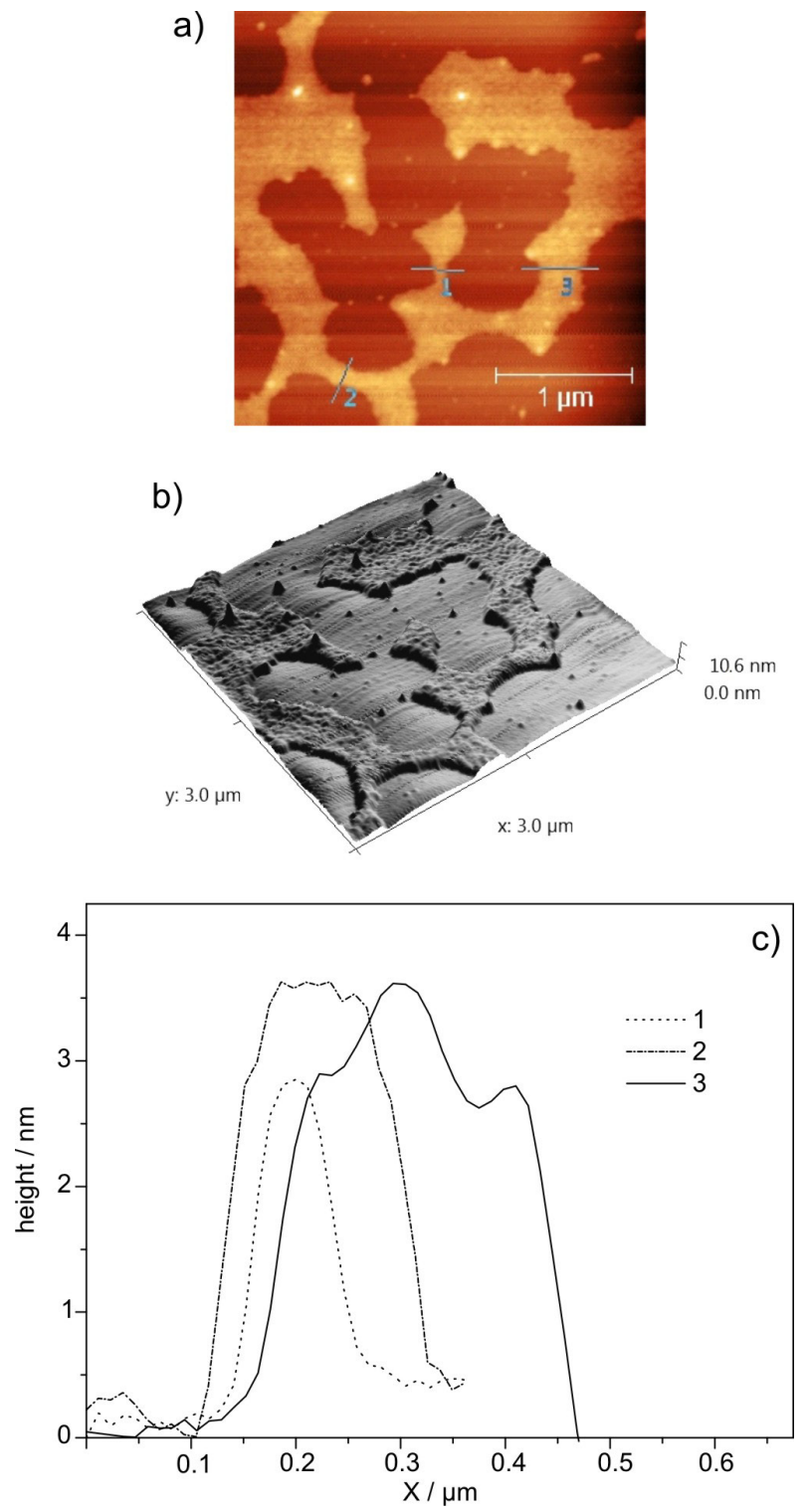

Figure 2. AFA AFM image at pH 9.0 in: a) 2D; b) 3D and c) height in function of images scanning, represented in the segments 1, 2 and 3 from Figure $2 \mathrm{a}$. ionization, with a gradual increase concentration of these groups from $\mathrm{pH}$ 7.0. Thus, the contribution of phenolic acids for the formation of AFA negative charges in solution is more important than the carboxylic groups.

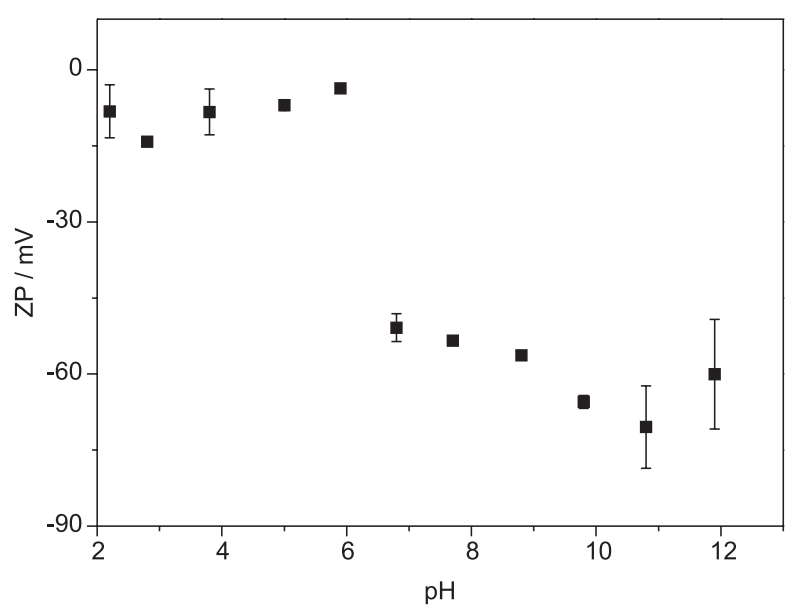

Figure 3. Zeta potential variation with the AFA sample $\mathrm{pH}$.

Balnois et al. ${ }^{23}$ using AFM images, reported that no aggregates were observed for the relatively hydrophilic Suwannee River humic acid between $\mathrm{pH} 3.0$ and pH 10.0. A different result in this work using a tropical river FA, was that aggregates were identified at $\mathrm{pH} 3.0$, and open structure at $\mathrm{pH} 9.0$.

In Figures 4 and 5, are seen some of the results by fluorescence spectroscopy. Figure 4 illustrates the emission mode fluorescence spectra obtained for the fulvic acid samples, at different $\mathrm{pH}$ values.

Figure 5 shows the contribution of at least four different fluorophore responsible for the AFA fluorescence at different $\mathrm{pH}$ values.

Determining parameters such as height, width, area and Gaussian position regarding the possible fluorophore present in the AFA, were obtained (Table 2). Increase in the Gaussian area is observed with the decrease in $\mathrm{pH}$.

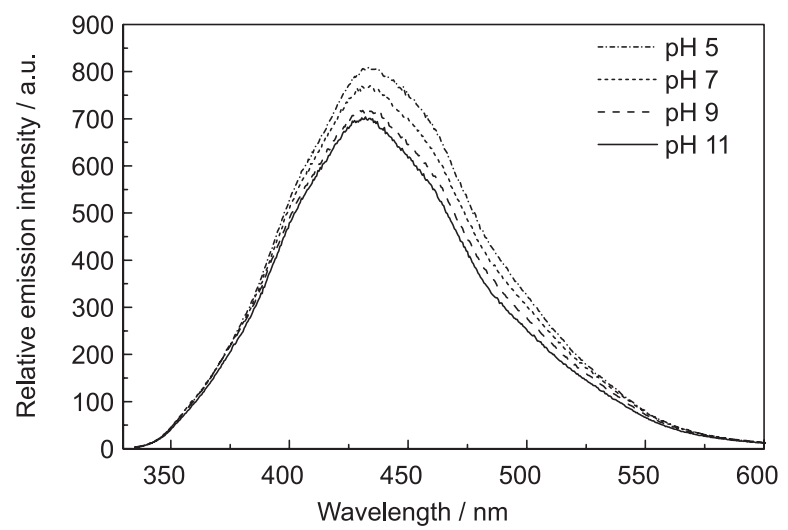

Figure 4. Emission mode fluorescence spectra, with $320 \mathrm{~nm}$ excitation, obtained for the AFA sample, at different $\mathrm{pH}$ values; $8 \mathrm{mg} \mathrm{L}^{-1} \mathrm{NaHCO}_{3}$. 

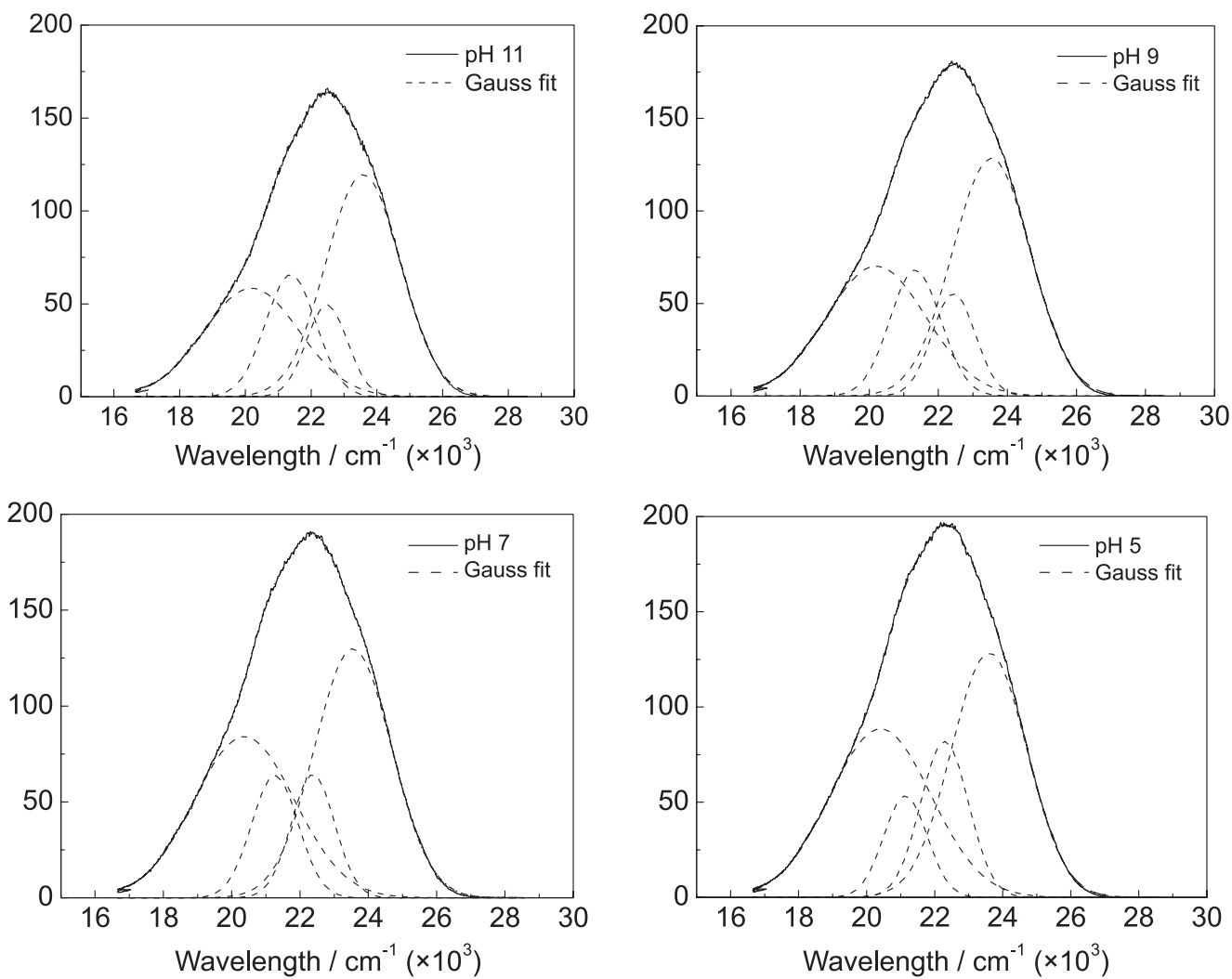

Figure 5. Fluorescence spectra obtained for the AFA sample, with $320 \mathrm{~nm}$ excitation, at different $\mathrm{pH}$ values. Adjustment of the Gaussian function shows the possible participation of at least four compounds in the band formation.

Table 2. Parameters determined for the Gaussians referring to possible fluorophore present in AFA, at different $\mathrm{pH}$ values, obtained from the emission mode spectra, with one data in wavenumber

\begin{tabular}{|c|c|c|c|c|}
\hline \multirow[t]{2}{*}{ Gaussians } & \multicolumn{4}{|c|}{ Sample AFA } \\
\hline & Height & Width & Area & Position \\
\hline & \multicolumn{4}{|c|}{$\mathrm{pH} 5$} \\
\hline 1 & 88.540 & $2.97 \pm 0.04$ & $329.68 \pm 13.58$ & $20.40 \pm 0.06$ \\
\hline 2 & 53.435 & $1.27 \pm 0.06$ & $185.15 \pm 17.32$ & $21.14 \pm 0.06$ \\
\hline 3 & 82.081 & $1.40 \pm 0.07$ & $144.36 \pm 2.07$ & $22.29 \pm 0.05$ \\
\hline \multirow[t]{2}{*}{4} & 128.48 & $2.20 \pm 0.03$ & $366.82 \pm 14.00$ & $23.59 \pm 0.04$ \\
\hline & \multicolumn{4}{|c|}{$\mathrm{pH} 7$} \\
\hline 1 & 84.07 & $2.94 \pm 0.04$ & $309.98 \pm 14.04$ & $20.36 \pm 0.06$ \\
\hline 2 & 63.90 & $1.36 \pm 0.07$ & $128.97 \pm 18.09$ & $21.26 \pm 0.06$ \\
\hline 3 & 64.53 & $1.26 \pm 0.05$ & $102.22 \pm 17.45$ & $22.37 \pm 0.05$ \\
\hline \multirow[t]{2}{*}{4} & 130.00 & $2.24 \pm 0.02$ & $366.04 \pm 11.10$ & $23.55 \pm 0.03$ \\
\hline & \multicolumn{4}{|c|}{$\mathrm{pH} 9$} \\
\hline 1 & 70.21 & $2.89 \pm 0.05$ & $255.17 \pm 2.73$ & $20.20 \pm 0.07$ \\
\hline 2 & 68.20 & $1.47 \pm 0.08$ & $126.48 \pm 18.73$ & $21.33 \pm 0.06$ \\
\hline 3 & 55.64 & $1.24 \pm 0.05$ & $86.65 \pm 16.73$ & $22.44 \pm 0.04$ \\
\hline \multirow[t]{2}{*}{4} & 128.60 & $2.26 \pm 0.02$ & $355.24 \pm 10.27$ & $23.53 \pm 0.03$ \\
\hline & \multicolumn{4}{|c|}{ pH 11} \\
\hline 1 & 58.47 & $2.89 \pm 0.06$ & $212.49 \pm 13.05$ & $20.18 \pm 0.09$ \\
\hline 2 & 65.85 & $1.53 \pm 0.08$ & $126.19 \pm 20.26$ & $21.37 \pm 0.06$ \\
\hline 3 & 49.53 & $1.24 \pm 0.05$ & $77.45 \pm 17.07$ & $22.47 \pm 0.04$ \\
\hline 4 & 119.64 & $2.25 \pm 0.02$ & $338.47 \pm 9.61$ & $23.57 \pm 0.03$ \\
\hline
\end{tabular}


Thus, the increase in area with the decrease in $\mathrm{pH}$ suggests that protonation might contribute with effects and changes in the AFA molecular conformation. Multiple protonations of replacing fluorophore with aromatic structures, present in the fulvic acid, might increase total fluorescence induced by the protonation of acid functional groups at lower $\mathrm{pH} .{ }^{24}$ This hypothesis is confirmed by Figure 3 in which a decrease in negative charges (near zero) at acid $\mathrm{pH}$ in the AFA solution is observed.

Senesi et al.,$^{13}$ observed decrease in the fluorescence intensity in $\mathrm{HS}$ with the increase in $\mathrm{pH}$ at values higher than 6. Ghosh and Schnitzer, ${ }^{25}$ atributed these effects to the changes in macromolecular conformation, however, the authors also suggest that the decrease in fluorescence intensity is due to some change in $\lambda_{\text {max }}$, and decrease in absorptivity, due to the phenolic chromophoric substitutedcarboxyl, caused by alterations in $\mathrm{pH}$. This result confirms the AFM images (Figures 1 and 2) where changes in the AFA morphology were observed when the $\mathrm{pH}$ varied from 3.0 to 9.0 .

According to Visser et al.,${ }^{26}$ and Miano et al. ${ }^{27}$ with $\mathrm{pH}$ increase from 3.0 to 8.4 or 4.0 to 9.0 , for a 100 or $50 \mathrm{mg} \mathrm{L}^{-1}$ solutions, respectively, the emission band intensity decreases, meaning that the excitation peak increases significantly for the aqueous fulvic acid samples. In contrast with these experiments, the increase in the emission intensity, has been reported in literature, ${ }^{27}$ with the increase in turbid water. In fulvic acids in peat, for example, at a $50 \mathrm{mg} \mathrm{L}^{-1}$ concentration, the main peak intensity increases with the increase in $\mathrm{pH}$ from 4.0 to 9.4 , while the emission intensity showed a maximum at $\mathrm{pH} 7.0$ with reasonable decrease with the decrease in $\mathrm{pH}$ lower than 7.0 and a mild slope above $\mathrm{pH}(\mathrm{s}) 7.0$ and 9.4. ${ }^{27}$

In general, it has been considered that increase in the fluorescence intensity with the $\mathrm{pH}$ variation, might present great dependence on the high phenolic hydroxyl groups content. With increase of these ionized groups and decrease in associated particles and molecular structures, hydrogen inter and intramolecular bonding ${ }^{25,26}$ might break.

The increase of $\mathrm{OH}$ phenolic groups, in the fulvic acid samples, results in a increase in main peak excitation intensity. The opposite effect, that is, attenuation in the emission intensity might happen. ${ }^{26}$

Humic substances fluorescence is very sensitive to the $\mathrm{pH} .{ }^{25,27-29}$ As the fluorescence depends on the molecule conjugation degree and occurrence of intramolecular hydrogen, bonding might increase or decrease the neighboring groups conjugation. Then the fluorescence intensity might vary with the occurrence of this kind of bonding, according to the variation in electrolytes concentration and the $\mathrm{pH}^{25}$
The difference and contrast of results in literature, ${ }^{25}$ however, are not surprising if one considers the variety of functional groups in constant ionization in fulvic acids and the rearrangement in the molecular configuration that happens when there is $\mathrm{pH}$ variation. However, the difficulty to stabilish the aromatic compounds in the various stages of ionization and to predict the fluorescence relation with the sample $\mathrm{pH}$, related to compounds of unknown structure, has been emphasized.

$\mathrm{pH}$ dependence regarding fluorescence properties varies with the fulvic acid samples chemical nature. According to Visser et al. ${ }^{26}$ fluorescent units are only the minority of humic substances and the investigation of such minority might lead indirectly to valuable information about molecular characteristics and quantitative aspects of the general chemistry of these substances. However, the fluorescence properties of fulvic and humic acids, are apparently dependent on the number of parameters, including their origin, molecular mass, concentration, $\mathrm{pH}$, the means redox potential as well as their interaction with metallic ions.

\section{Conclusions}

This work showed that through atomic force microscopy techniques and fluorescence spectroscopy, structural change in fulvic acid of a Brazilian river was identified when the solution $\mathrm{pH}$ varied. Results suggest that in acid $\mathrm{pH}$ weak electrostatic interactions and hydrogen bonding are responsible for aggregates formation while in alkaline $\mathrm{pH}$ electrostatic interactions are strong due to increase in the phenolic groups ionization and low hydrogen interaction forming more open structures.

\section{Aknowledgments}

We are grateful to Finep and $\mathrm{CNPq}$ for financial support and Embrapa Instrumentação Agropecuária for use of AFM and Potencial Zeta facilities.

\section{References}

1. Carvalho, E. R.; Martin-Neto, L.; Milori, D. M. B. P.; Rocha, J. C.; Rosa, A. H.; J. Braz. Chem. Soc. 2004, 15, 421.

2. Maurice-Johnsson, P. A.; Parks, G. A.; Sposito, G.; Aiken, G. R.; Proceedings of 207th National Meeting, ACS Division of Environmental Chemistry, San Diego, USA, 1994.

3. Lindsay, W. L.; Plant Soil 1991, 130, 27.

4. Ochs, M.; Brunner, L.; Stumm, W.; Cosovic, B.; Water, Air, Soil Pollut. 1993, 68, 213.

5. Maurice, P.A.; Hochella, M. F., Jr.; Parks, G. A.; Sposito, G.; Schwcrtmann, U.; Clays Clay Miner. 1995, 43, 29. 
6. Tan, K. H.; Humic Matter in Soil and Environment, Principles and Controversies, Marcel Dekker, Inc.: New York, 2003, p. 386 .

7. Saab, S. C.; Martin-Neto, L.; J. Braz. Chem. Soc. 2004, 15, 34.

8. Saab, S. C.; Martin-Neto, L.; Quim. Nova 2007, 30, 260.

9. Saab, S. C.; Martin-Neto, L.; J. Braz. Chem. Soc. 2008, 19, 413.

10. Favoretto, C. M.; Milori, D. M. B. P.; Rosa, J. A.; Leite, W. C.; Brinatti, A. M.; Saab, S. C.; Quim. Nova 2008, 31, 1994.

11. Chen, C.; Wang, X.; Jiang, H.; Hu, W.; Colloids Surf., A 2007, 302, 121.

12. Namjesnik-Dejanovic, K.; Maurice, P. A.; Colloids Surf., A 1997, 120, 77.

13. Senesi, N.; Miano,T. M.; Provenzano, M. R.; Brunetti, G.; Soil Sci. 1991, 152, 259.

14. Milori, D. M. B. P; Martin-Neto, L.; Bayer, C.; Mielniczuk, J.; Bagnato, V. S.; Soil Sci. 2002, 167, 739.

15. Leite, F. L.; Herrmann, P. S. P.; J. Adhes. Sci. Technol. 2005, $19,365$.

16. Plaschke, M.; Rothe, J.; Schäfer, T.; Denecke, M. A.; Dardenne, K. S.; Pompe, K. Heise, H.; Colloids Surf., A 2002, 197, 245.

17. Gorham, J. M.; Wnuk, J. D.; Shin, M.; Fairbrother, H.; Environ. Sci. Technol. 2007, 41, 1238.

18. Mertig, M.; Klemm, D.; Pompe, W.; Zanker, H.; Bottger, M.; Surf. Interface Anal. 1999, 27, 426.

19. Chen, Y.; Schnitzer, M.; Soil Sci. Soc. Am. J. 1976, 40, 682.
20. Malcolm, R. L. In Humic Substances in the Aquatic and Terrestrial Environment; Allard, B.; Boren H.; Grimvall, A., eds.; Springer-Verlag: Berlim, 1989, p. 9.

21. http://gwyddion.net/, accessed in July 2008.

22. Alvarez-Puebla, R. A.; Garrido, J. J.; Chemosphere 2005, 59, 659.

23. Balnois, E.; Wilkinson, K. J.; Lead, J. R.; Buffle, J.; Environ. Sci. Technol. 1999, 33, 3911.

24. Saar, R. A.; Weber, H. J.; Environ. Sci. Technol. 1982, 16, 510 A.

25. Ghosh, K.; Schnitzer, M.; Soil. Sci. Soc. Am. J. 1980, 44, 975.

26. Visser, S. A.; Christman, R. F.; Gjessing, E. T.; Aquatic and Terrestrial Humic Materials, Ann Arbor Science: Ann Arbor, 1983.

27. Miano, T. M.; Sposito, G.; Martin, J. P.; Soil Sci. Soc. Am. J. 1988, 52, 1016.

28. Stevenson, F. J.; Humic Substances in the Global Environment and Implications on Human Health, Elsevier Scientific: Amsterdam, 1994.

29. Zsolnay, A.; Baigar, E.; Jiménez; M.; Steinweg, B.; Saccomandi, F.; Chemosphere 1999, 38, 45.

Received: October 8, 2009

Web Release Date: April 12, 2010

FAPESP has sponsored the publication of this article. 